\title{
CALCULATION AND EXPERIMENTAL ESTIMATION OF RESULTS OF ELECTRO-THERMAL ACTION OF RATIONED BY THE INTERNATIONAL STANDARD IEC 62305-1-2010 IMPULSE CURRENT OF SHORT BLOW OF ARTIFICIAL LIGHTNING ON THE THIN-WALLED COVERAGE FROM STAINLESS STEEL
}

Purpose. Calculation and experimental researches of electro-thermal resistibility of the pre-production thin-walled sheet models of outward roof of height technical buildings from stainless steel are easily soiled 12X18H10T to direct action on them rationed by the International Standard IEC 62305-1-2010 aperiodic impulse of current of short bow of artificial lightning of temporal form 10/350 $\mu$ with the proper admittances on his peak-temporal parameters (PTP). Methodology. Electrophysics bases of technique of high voltage and large impulsive currents (LIC), and also scientific and technical bases of planning of high-voltage impulsive devices and measuring methods in them LIC with followings below extreme PTP: amplitude of impulse of current of $I_{m L}=200 \kappa A$ (with admittance $\pm 10 \%$ ); integral of action of impulse of current of $J_{L}=10 \cdot 10^{6} A^{2} \cdot s$ (with admittance $\left.\pm 35 \%\right)$; \%); duration of wavefront current of $T_{1}=10 \mu \mathrm{s}$ (with admittance $\pm 20 \%$ ); time, proper amplitude of impulse of current of $I_{m L}, t_{m L} \leq 24$ $\mu s$ (with admittance $\pm 20 \%$ ); duration of flowing of impulse of current of $T_{2}=350 \mu$ s (with admittance $\pm 10 \%$ ). Results. The results of evaluation calculation and experimental researches of electro-thermal resistibility of the indicated pre-production sheet models are resulted measuring in the plan of 0,5 $x 0,5 \mathrm{~m}$ from stainless steel are easily soiled the 12X18H10T thickness of $1 \mathrm{~mm}$ to action on them of aperiodic impulse of current of short blow of artificial lightning with rationed PTP on the requirements of the International Standard IEC 62305-1-2010. In high current experiments amplitude of $I_{m L}$ of the aperiodic rationed impulse of current of artificial lightning of temporal form of $T_{1} / T_{2}=15 \mu \mathrm{s} / 315 \mu \mathrm{s}$ changed in the range of (100-184) $\kappa A$. The integral of action of $J_{L}$ of impulse of current for I-IV of levels of protection of lightning of technical objects (TO) numeral made from $2,32 \cdot 10^{6} A^{2} \cdot s$ to $7,88 \cdot 10^{6} A^{2} \cdot s$, and the flowing through the probed pre-production steel models electric charge of $q_{L}$ numeral changed from 44,2 $\mathrm{Kl}$ to $81,3 \mathrm{Kl}$. It is shown that direct influence rationed by the International Standard IEC 62305-1-2010 impulse of current of short blow of artificial lightning with in-use PTP on the indicated pre-production steel models causes in them the rounded small hole of melting of surface of coverage a depth no more than $50 \mu m$ and diameter no more than 60 mm. The results of calculation and experiment coincide within the limits of $5 \%$. Originality. First in world practice on the unique generator of LIC of short blow of artificial lightning of type of GITM-10/350 experimental researches of electro-thermal resistibility of pre-production sheet models of outward roof are conducted TO of stainless steel 12X18H10T is easily soiled to direct action on them of impulses of current of an artificial storm air spark digit with extreme parameters. Practical value. Drawing on the got results in practice of protection height TO from linear lightning will allow substantially to promote their functional and fire-prevention safety in the conditions of direct action on them of the plasma ductings of high current storm air spark discharge. References 20, tables 1, figures 4.

Key words: artificial lightning impulse current of temporary shape $10 / 350 \mu$ s, thin-walled coverage made of stainless steel, electro-thermal effect of lightning current to the steel cover, radius and depth of penetration of the steel wall coverage, calculation and experimental estimation of damage zone of coverage.

Приведены результаты расчетной и опытной оценки электротермической стойкости тонкостенного покрытия наружной кровли высотного технического сооружения из нержавеющей стали марки 12Х18Н10Т к прямому воздействию на него нормированного по международному стандарту ІЕС 62305-1-2010 апериодического импульса тока искусственной молнии временной формы 10/350 мкс с амплитудой от 100 до 200 кА и заданными допусками на его амплитудно-временные параметры. Показано, что указанный импульсный ток молнии вызывает лишь локальное поверхностное термическое повреждение исследуемого стального покрытия при радиусе данной зоны повреждения не более 30 мм и глубине проплавления его стенки не более 50 мкм. Библ. 20, табл. 1, рис. 4.

Ключевые слова: импульс тока искусственной молнии временной формы 10/350 мкс, тонкостенное покрытие из нержавеющей стали, электротермическое действие тока молнии на стальное покрытие, радиус и глубина зоны проплавления стенки стального покрытия, расчетная и опытная оценка зоны повреждения покрытия.

Introduction. In [1] the authors presented the results of computational and experimental studies electrothermal resistance experienced sheet of thin $(1 \mathrm{~mm}$ thick and the size in terms of $500 \times 500 \mathrm{~mm}$ ) of the samples of the outer roof of stainless steel $12 \mathrm{X} 18 \mathrm{H} 10 \mathrm{~T}$ tall technical installations to the direct impact on their valuation $A$ - and $C$ - pulse current component of artificial lightning, amplitude and timing parameters (ATP) which comply with current regulatory requirements of the United States SAE ARP 5412 and SAE ARP 5416 documents in relation to the aircraft $[2,3]$. As is known, in this case, the impulse damped sinusoidal $A$ - lightning current component characterized by the following normalized ATP $[2,3]$ : current amplitude $I_{m A}= \pm 200 \mathrm{kA}$ (with tolerance of $\pm 10 \%$ ); the integral action of the 
current $J_{A}=2 \cdot 10^{6} \mathrm{~A}^{2} \cdot \mathrm{s}$ with (with tolerance of $\pm 20 \%$ ); time corresponding to the amplitude of the current $I_{m A}$ constituting $t_{m A} \leq 50 \mu \mathrm{s}$; the duration of the current flow $\tau_{p A} \leq 500 \mu \mathrm{s}$. Long aperiodic $C$ - lightning current component in this case had the following normalized ATP [2, 3]: amplitude $I_{m C}= \pm(200-800)$ A current; moved electric charge current $q_{C}= \pm 200 \mathrm{C}$ (with tolerance of \pm $20 \%)$; the duration of the current flow $\tau_{p C}=(0.25-1) \mathrm{s}$. Note that in [1], corresponding experiments were performed on designed and developed in 2007 at the experimental polygon at the Scientific-\&-Research Planning-\&-Design Institute «Molniya» of the NTU «KhPI» (at the Department No. 4 «Electromagnetic research and testing»), a powerful high-voltage generators of artificial lightning current УИТОМ-1 [4] is formed on the test technical object (TO) ATP current pulses from lightning described the $A$ - and $C$ - components on the requirements of the normative documents [2, 3]. According to the applicable requirements of the International Standard IEC 62305-1-2010 [5] in the assessment of protection from lightning strike short of buildings, technical installations and their parts, including those in which people and utilities, using a normalized aperiodic current pulse lightning temporary form $T_{1} / T_{2}=$ $10 \mu \mathrm{s} / 350 \mu \mathrm{s}$ of positive polarity, where $T_{1}, T_{2}$ are, respectively, the rise time and duration of the halftime of the lightning current pulse. Other highlights of the ATP for the lightning current impulse I lightning certain level characterized by the following numerical values [5]: the current amplitude $I_{m L}=200 \mathrm{kA}$ (with tolerance of $\pm 10 \%$ ); the integral action of the current (energy density) $J_{L}=10 \cdot 10^{6} \mathrm{~A}^{2} \cdot \mathrm{s}$ with (with tolerance of $\pm 35 \%$ ); the amount of electric charge leaked $q_{L}=100 \mathrm{C}$ (with tolerance of $\pm 20 \%$ ). For level II lightning TO have the following numerical values [5] considered ATP lightning current: current amplitude $I_{m L}=150 \mathrm{kA}$ (with tolerance of $\pm 10 \%$ ); current action integral (energy density) $J_{L}=5.6 \cdot 10^{6} \mathrm{~A}^{2} \cdot \mathrm{s}$ (with tolerance of $\pm 35 \%$ ); the amount of electric charge leaked $q_{L}=75 \mathrm{C}$ (with a tolerance of $\pm 20 \%$ ).

For most low III-IV levels of lightning then these ATP lightning current must meet the following specifications [5]: current amplitude $I_{m L}=100 \mathrm{kA}$ (with tolerance of $\pm 10 \%$ ); the integral action of the current (energy density) $J_{L}=2,5 \cdot 10^{6} \mathrm{~A}^{2} \cdot \mathrm{s}$ (with tolerance of \pm $35 \%$ ); the amount of electric charge leaked $q_{L}=50 \mathrm{C}$ (with tolerance of $\pm 20 \%$ ). In this context, an undoubted practical interest electrophysical task associated with the assessment of electro-thermal resistance of thin sheeting, stainless steel outer roof of high-rise buildings to direct technical impact on their aperiodic short strike lightning current pulse temporal shape $10 / 350 \mu$ s with ATP presented in [5].

The goal of the paper is the determination of the effects on the thin-walled sheeting made of stainless steel, mounted on the roof of high-rise buildings technical, short-current pulse of lightning strike with normalized according to the International Standard IEC 62305-1-2010 ATP.

1. Definition of the research problem of electrothermal resistance of thin-walled steel coating to the lightning current impulse $10 / 350 \mu \mathrm{s}$. In this applied research, consider a flat sheet thin-walled steel coating thickness $h \leq 1 \mathrm{~mm}$ is tested in the air with a steady temperature $\theta_{0}$ direct impact on it of a high plasma cylindrical channel short lightning with pulse aperiodic current $i_{L}(t)$, the relevant technical requirements [5]. Let the lightning channel in the area of its peg on the outer surface of the steel covering made of stainless steel $12 \mathrm{X} 18 \mathrm{H} 10 \mathrm{~T}$ [1], has a maximum radius $r_{0}$ satisfying in the SI system at the location of the protected by the known Braginsky formula [6]: $r_{0} \approx 0.093 \cdot\left(I_{m L}\right)^{1 / 3} \cdot\left(t_{m L}\right)^{1 / 2}$, where $I_{m L}$ is the the amplitude of the temporal shape of the lightning current aperiodic pulse $10 / 350 \mu$ s and $t_{m L}$ is the time corresponding to the amplitude of the current $I_{m L}$. Let us assume that the value of $t_{m L}$ is approximated by the ratio of the form [7]: $t_{m L} \approx 1.6 \cdot T_{1}$. We believe that the pulse current density $\delta_{L}$ and heat flux in a cylindrical $g_{L}$ lightning plasma channel substantially uniformly distributed over the cross section of its circular $S_{k}=\pi r_{0}{ }^{2}$. One evidence of this is that virtually characterized by uniform distribution of its radius $r_{0}$ [8] in the high channel electric gas discharge electron and ion thermodynamic temperature of its lowtemperature plasma in a first approximation. We believe that in the course of the impact of lightning channel considered thin-walled steel cover round the zone of its binding radius $r_{0}$ remains almost stationary relative to the covering wall. We accept the assumption that the volume $V_{0}$ of the molten aperiodic impulse lightning $i_{L}(t)$ the current metal coating determines ultimately the amount of damage zone under suitable conditions and the form of its area of penetration. The calculated evaluation of the results of said electrothermal action of a high cylindrical channel of lightning on the steel cover to do the assumption of immutability in the short strike lightning basic thermal characteristics of the material under consideration of the TO coating.

2. The calculation estimation of results of the electro-thermal effects on the thin-walled steel cover the lightning current impulse $10 / 350 \mu \mathrm{s}$. It is known that thermal damage to the metal and insulation (composite), then elements in the field of direct lightning strike in them due to the presence of intense heat flux in the plasma channel of a lightning discharge [9]. $g_{L}$ density of heat flow in the channel of lightning, acting on the test steel cover TO determined $\delta_{L}$ current density in it (the channel) and the fall of the voltage $U_{a c}$ in the electrode area of the plasma channel considered high-current discharge. We can use the following approximate relation $[10,11]$ to assess the magnitude of the heat flux density gL flowing in the steel cover (in one of the electrodes in the estimated two-electrode system air lightning) TO: 


$$
g_{L}=\delta_{L} \cdot U_{a c},
$$

where $U_{a c}$ is the the value of the near-electrode voltage drop in steel coating, performing in a two-electrode system (TES) as a cathode at a predetermined positive polarity lightning current.

According to the experimental data presented in [10], the value for the basic $U_{a c}$ conductive materials TES calculation used in aircraft (ground) and other apparatuses TO varies within a narrow range of from 5 to $10 \mathrm{~V}$ applied to the steel under consideration covering the value of the cathode $U_{a c}$ numerically is about $6.1 \mathrm{~V}$ [10]. Then, taking into account (1) the amount of heat the $Q$ entering the steel cover with a direct strike of lightning in it, we can write the calculated expression:

$$
Q=\pi \int_{0}^{\infty} g_{L} r_{0}^{2} d t=\pi U_{a c} \int_{0}^{\infty} \delta_{L} r_{0}^{2} d t=U_{a c} q_{L},
$$

where $q_{L}=\int_{0}^{\infty} i_{L}(t) d t$ is the amount of electric charge of positive polarity of the plasma channel lightning flowing through the steel cover.

On the other hand, for the $Q$ value of the amount of heat, to stand out in a steel coating material at his defeat by direct lightning strike, will have the following calculated relation [12]:

$$
Q=m_{0}\left[C_{0}\left(\theta_{m}-\theta_{0}\right)+C_{m}\right]
$$

where $m_{0}=d_{0} V_{0}$ is the mass of heated impulse lightning current to the melting temperature $\theta_{m}$ coating material having the density $d_{0}$ and volume $V_{0} ; C_{0}$ is the heat capacity of the coating material; $C_{m}$ is the specific heat of melting of the coating material.

2.1. The calculation estimation ov volume of the melting zone in the wall of a steel cover. From (2) and (3) for the magnitude of the volume $V_{0}$ of the molten coating material steel TO when exposed to short lightning obtain the estimated expression of the form:

$$
V_{0}=U_{a c} q_{L} d_{0}^{-1}\left[C_{0}\left(\theta_{m}-\theta_{0}\right)+C_{m}\right]^{-1} .
$$

From (4) we see that we obtained above approximate electrophysical by design analytical expression for finding molten pulse aperiodic current of lightning $i_{L}(t)$ of the volume $V_{0}$ thin-walled steel that cover is fully consistent with the estimated ratio recommended in this case, according to [5] the International Standard IEC 62305-1-2010 (see in [5] Annex D, formula D.9). Below Table 1 shows the numerical data for the major electrical and thermal parameters we used steel grades for thin-wall coatings TO roof.

Then from (4) and the data of Table 1 it implies that the calculated estimate of the molten short lightning $V_{0}$ volume of the coating metal TO is necessary to know only the amount of electric charge $q_{L}$ leaked through the test coverage. To find the charge on $q_{L}$ (2) using the following analytical expression for aperiodic lightning current impulse $i_{L}(t)$ of temporary form of $10 / 350 \mu$ s flowing through the coating TO $[14,15]$ :

$$
i_{L}(t)=k_{L} I_{m L}\left[\exp \left(-\alpha_{1} t\right)-\exp \left(-\alpha_{2} t\right)\right]
$$

where $\alpha_{1} \approx 0,76 / T_{2}, \alpha_{2} \approx 2,37 / T_{1}$ are the coefficients of the lightning current with an aperiodic pulse given ATP; $k_{L}=\left[\left(\alpha_{1} / \alpha_{2}\right)^{\beta}-\left(\alpha_{1} / \alpha_{2}\right)^{\gamma}\right]^{-1}$ is the normalizing factor; $\beta=\alpha_{1} /\left(\alpha_{2}-\alpha_{1}\right) ; \gamma=\alpha_{2} /\left(\alpha_{2}-\alpha_{1}\right)$.

As a result, taking into account (5) for the quantity of electric charge $q_{L}$, flowing at the time used the form of $T_{1} / T_{2}=10 / 350 \mu \mathrm{s}$ aperiodic current pulse through the susceptibility of short thunderbolt investigated steel cover TO, we find:

$$
q_{L}=\int_{0}^{\infty} i_{L}(t) d t \approx k_{L} I_{m L}\left[1,315 T_{2}-0,422 T_{1}\right]
$$

Table 1

Main electric and thermal properties for steel $12 \mathrm{X} 18 \mathrm{H} 10 \mathrm{~T}$ at room temperature $\left(\theta_{0}=20^{\circ} \mathrm{C}\right)$ of air media $[1,10,13]$

\begin{tabular}{|c|c|c|}
\hline Parameter & Dimensionality & Value \\
\hline$U_{a c}$ & $\mathrm{~V}$ & 6.1 \\
\hline$d_{0}$ & $\mathrm{~kg} / \mathrm{m}^{3}$ & 7900 \\
\hline$C_{0} /\left(\mathrm{kg} \cdot{ }^{\circ} \mathrm{C}\right)$ & 462 \\
\hline$\theta_{m}$ & ${ }^{\circ} \mathrm{C}$ & 1455 \\
\hline$C_{m}$ & $\mathrm{~J} / \mathrm{kg}$ & $84 \cdot 10^{3}$ \\
\hline
\end{tabular}

Estimated numerical estimate of the charge $q_{L}$ on the proposed equation (6) shows that, at a given time form $T_{1} / T_{2}=10 / 350 \mu$ s lightning current impulse $i_{L}(t)$ to (5) with the contact found normalizing factor $k_{L} \approx 1.054$ and normalized according to the specifications requirements [5] The amplitude of this pulse current $I_{m L}=100 \mathrm{kA}$ and $I_{m L}=200 \mathrm{kA}$ it (the quantity $q_{L}$ charge) accepts numerical values, respectively 48.1 and $96.2 \mathrm{C}$. These estimates for (6) the values $q_{L}$ charge for the above two cases, only normalized to no more than $4 \%$ different from his (charge) corresponding to normalized values by taking requirements [5] numerical indicators 50 and $100 \mathrm{C}$. Taking into account the last relation (6) can be used in the field of lightning protection TO estimates the value of the electric charge $q_{L}$ flowing through the metal coating then the direct impact it short lightning.

In determining the effects of electro-thermal effects of a lightning strike on a short metal or insulation (composite) cover TO something important parameter of this action is normalized in [5] the integral action $J_{L}$ lightning surge current $i_{L}(t)$ (the specific energy with the dimension $J / \Omega$ ). Using (5), for the current integral action $J_{L}$ aperiodic pulse lightning $i_{L}(t)$ of temporary form of $T_{1} / T_{2}=10 / 350 \mu$ s to our approximation we obtain the following estimated ratio: 


$$
J_{L}=\int_{0}^{\infty} i_{L}^{2}(t) d t \approx k_{L}^{2} I_{m L}^{2}\left[0,658 T_{2}-0,633 T_{1}\right] .
$$

From (7) at $T_{1} / T_{2}=10 / 350 \mu \mathrm{s}\left(k_{L} \approx 1.054\right)$ in regulated by the requirements of [5] when $I_{m L}=100 \mathrm{kA}$ or $I_{m L}=200$ $\mathrm{kA}$ it follows that the value of the integral action $J_{L}$ received aperiodic lightning current pulse $i_{L}(t)$ takes respectively calculated numerical values of $2.49 \cdot 10^{6}$ and $9.96 \cdot 10^{6} \mathrm{~A}^{2} \cdot \mathrm{s}$. These estimates we obtained the value of the integral action $J_{L}$ considered lightning impulse current of not more than $1 \%$ different from the normalized with [5] numerical values $J_{L}$ constituting respectively $2.5 \cdot 10^{6}$ и $10 \cdot 10^{6} \mathrm{~A}^{2} \cdot \mathrm{s}$. Therefore, the relation (7) can be used in the field of lightning protection then the estimates of the value of a temporary form of a lightning current integral action $J_{L}$ aperiodic pulse $T_{1} / T_{2}=10 / 350 \mu$ s acting on metallic or insulating (composite) coating protected TO.

2.2. The calculation estimation of the depth of penetration of the hole wall of the steel cover. From (4) and cylindrical form specified radius $r_{0}$ wells of thermal damage to the outside of the surface of the flat metal coating TO that is because of the action of a high lightning channel to a depth of penetration wells $h_{m}$ we obtain:

$$
h_{m}=36,8 \cdot U_{a c} q_{L} d_{0}^{-1} I_{m L}^{-2 / 3} t_{m L}^{-1}\left[C_{0}\left(\theta_{m}-\theta_{0}\right)+C_{m}\right]^{-1} .
$$

From (8) at the normalized amplitude $I_{m L} \approx 184 \mathrm{kA}$ short stroke current pulse form of artificial lightning time $T_{1} / T_{2}=15 / 315 \mu \mathrm{s}\left(t_{m L} \approx 24 \mu \mathrm{s} ; k_{L} \approx 1.083 ; q_{L} \approx 81.3 \mathrm{C}\right)$ we simulated in the laboratory (see. section 4 below), and the source of electricity and thermal parameters for stainless steel thin-walled $12 \mathrm{X} 18 \mathrm{H} 10 \mathrm{~T}$ considered $(h \leq 1 \mathrm{~mm})$ covering TO in Table 1, for the depth of penetration $h_{m}$ wells should be that it is numerically approximately 39.8 $\mu \mathrm{m}$. The maximum radius $r_{0} \approx 0.093 \cdot\left(I_{m L}\right)^{1 / 3} \cdot\left(t_{m L}\right)^{1 / 2}$ cylindrical penetration holes for the steel cover is numerically equal to about $25.9 \mathrm{~mm}$.

2.3. The calculation estimation of the radius of penetration holes through the wall of the steel cover. On the basis of (4), for thin-walled steel cover when taking into account (8) the condition of penetration through aperiodic pulse lightning current $i_{L}(t)$ of temporary form $T_{1} / T_{2}=10 / 350 \mu \mathrm{s}$ its wall $h_{m} \geq h$, the estimated ratio for the radius $r_{m}$ penetration hole through the wall of the test coverage takes the following approximate form:

$$
r_{m}=\left\{U_{a c} q_{L}\left(\pi \pi h_{0}\right)^{-1}\left[C_{0}\left(\theta_{m}-\theta_{0}\right)+C_{m}\right]^{-1}\right\}^{1 / 2} .
$$

Quantitative evaluation on (9) of the radius $r_{m}$ round hole through the wall penetration of the steel under consideration cover the thickness of the micrometers $\mathrm{h} \approx \mathrm{hm} \approx 40$ short lightning with these normalized to [5] values ATP pulse current $\left(I_{m L} \approx 184 \mathrm{\kappa A} ; T_{1} \approx 15 \mu \mathrm{s} ; T_{2} \approx 315\right.$ $\mu \mathrm{s} ; k_{L} \approx 1.083 ; q_{L} \approx 81.3 \mathrm{C}$ ) shows that in this case, it takes a numerical value equal to approximately $25.9 \mathrm{~mm}$. It is evident that in this approximation the numerical value of the radius $r_{m}$ of the hole of the keyhole cover walls practically corresponds to the calculated value of the maximum radius $r_{0}$ lightning channel defined by the Braginsky formula above [6]. This result indicates the validity of the calculation of (9).

3. The calculation estimation of the temperature of the plasma channel high-current lightning spark discharge air. With an integrated approach to the problem before us electrophysical professionals is important to orient in the numerical temperature levels, resulting in high air spark discharges of lightning and a direct impact on the external elements of protected TO. In this case, we assume that the condition of its nonisothermal in which it (plasma) the maximum temperature $T_{m e}$ electronic charge carriers exceeds the maximum temperature $T_{m i}$ carriers ion current $\left(T_{m e}>T_{m i}\right)$ for the lowtemperature plasma of a high air spark lightning at times $t \leq t_{m L}$ [12]. Using the results of applied research, presented in $[11,15]$, to the maximum of the electron temperature of the plasma channel $T_{m e}$ short lightning in the air under normal conditions (air pressure is $1.013 \cdot 10^{5} \mathrm{~Pa}$ and at a temperature equal to $\left.\theta_{0}=0{ }^{\circ} \mathrm{C}[12]\right)$ we can write the following approximate ratio calculated:

$$
T_{m e} \approx 3,28 \cdot \sqrt[4]{I_{m L}^{1 / 3} U_{a c} /\left(\sigma_{c} t_{m L}\right)},
$$

where $\sigma_{c}=5.67 \cdot 10^{-8} \mathrm{~W} \cdot\left(\mathrm{m}^{2} \cdot \mathrm{K}^{4}\right)^{-1}$ is the Stefan-Boltzmann constant.

Substituting in (10) at $\sigma_{c}=5.67 \cdot 10^{-8} \mathrm{~W} \cdot\left(\mathrm{m}^{2} \cdot \mathrm{K}^{4}\right)^{-1}$ and $U_{a c}=6.1 \mathrm{~V}$ the corresponding numerical data source for standardized requirements for [5] aperiodic pulse temporal shape of the lightning current $T_{1} / T_{2}=10 / 350 \mu \mathrm{s}$ $\left(I_{m L} \approx 2 \cdot 10^{5} \mathrm{~A} ; t_{m L} \approx 16 \cdot 10^{-6} \mathrm{~s}\right)$ we find that in the test case, the maximum electron temperature plasma $T_{m e}$ channel high-current lightning discharge air is numerically $T_{m e} \approx 14.6 \cdot 10^{3} \mathrm{~K}$. it should be noted that the obtained by (10) the numerical value for the electron $T_{m e}$ temperature is in good agreement with those given in $[16,17]$ known experimental results for the considered temperature plasma high-channel air spark discharges are widely used in electrotechnology, based on the basis of a high-voltage pulse technology [18].

4. Experimental evaluation of the influence on the electro-walled steel cover the lightning current impulse 10/350 $\boldsymbol{\mu s}$. The experimental verification of its operation some given us the calculated relations (in particular, (4), (6), (8) and the Braginsky formula for $r_{0}$ ) will perform at the designed and developed at the Scientific-\&-Research Planning-\&-Design Institute «Molniya» of the NTU «KhPI» in 2014, a unique powerful high-voltage generator type ГИТМ-10/350 $[19,20]$, modeling on low-resistance and lowinductance electrical load aperiodic pulses temporary form $T_{1} / T_{2}=10 / 350 \mu$ s of artificial lightning current in accordance with the requirements of the International 
Standard IEC 62305-1-2010 [5] . To this end, the air discharge circuit TES of high ГИТМ-10/350 placed on the desktop of the high voltage generator, at $\theta_{0} \approx 20{ }^{\circ} \mathrm{C}$ experienced sheet samples were placed in stainless steel $12 \mathrm{X} 18 \mathrm{H} 10 \mathrm{~T}$ having a size in terms of $500 \times 500$ $\mathrm{mm}$ and thickness $h=1 \mathrm{~mm}$. Note that TES used in experiments with the top electrode of cylindrical shape $25 \mathrm{~mm}$ in diameter, made of Steel 3, the length of the air gap between its rounded along the radius about 12.5 $\mathrm{mm}$ and experienced edge sheet sample of stainless steel 12X18H10T was approximately $14 \mathrm{~mm}$. To initiate a steel model of an experienced high-current spark discharge plasma channel short artificial lightning strike in the air gap TES placed a thin copper wire $0.2 \mathrm{~mm}$ in diameter and about $37 \mathrm{~mm}$ in length, anchored at its upper steel electrode and a suitable normal to the top of the prototype steel roof plane TO with an air gap of approximately $3 \mathrm{~mm}$.

Measurement of ATP of aperiodic artificial lightning current pulse is generated in the high-current discharge circuit ГИТМ-10/350 and acting on the prototype sample sheet steel roofing TO carried out with the help of agents of the state metrological service measuring coaxial shunt type ШК-300 [4] having a conversion factor $K_{m L} \approx 10417 \mathrm{~A} / \mathrm{V}$, and digital storage oscilloscope Tektronix TDS 1012. Fig. 1 shows the waveform obtained in this case with the help of the ГИТМ-10/350 aperiodic pulse current $i_{L}(t)$ of positive polarity artificial lightning during a thunderstorm short air discharge.

We point out that in the preparation shown in Fig. 1 waveform deadbeat artificial lightning current pulse in the high-voltage high-current discharge circuit ГИТМ-10/350 three of his pulse current generator (PCG) contained in the total amount of 171 pieces parallel and charged to a constant voltage $U_{c 1-3} \approx 17 \mathrm{kV}$ high-voltage pulse capacitors type ИК-50-3 and the fourth PCG was built on the basis of 288 pieces serialto-parallel and parallel-charged to a constant voltage $U_{c 4} \approx 4.5 \mathrm{kV}$ high-voltage pulse ИМ 2-5-140 type capacitors (on their way out) $[19,20]$. From the data in Fig. 1 implies that the impact in this case on a sample of experienced sheet steel roofing impulse short stroke artificial lightning current is generally consistent with the stringent requirements of the International Standard IEC 62305-1-2010 [5] for the III-IV levels of lightning TO. Proof of this is that the main ATP flowing through an experienced steel sample the thickness $h=1 \mathrm{~mm}$ normalized simulated lightning current pulse at the same time have the following numerical values: $I_{m L} \approx 100 \quad \mathrm{kA} ; \quad T_{1} \approx 15 \mu \mathrm{s} ; \quad T_{2} \approx 315 \mu \mathrm{s} ; \quad q_{L} \approx 44.2 \quad \mathrm{C}$; $J_{L} \approx 2.32 \cdot 10^{6} \mathrm{~A}^{2} \cdot \mathrm{s}$.

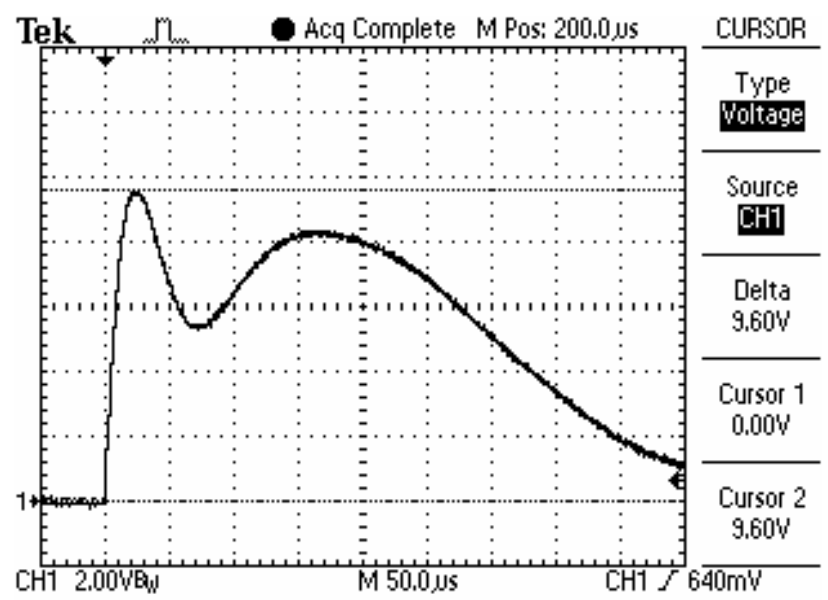

Fig. 1. Waveform current normalized aperiodic pulse temporal shape of artificial lightning $15 / 315 \mu$ s with an amplitude $I_{m L}$ $\approx 100 \mathrm{kA}\left(q_{L} \approx 44.2 \mathrm{C} ; J_{L} \approx 2.32 \cdot 10^{6} \mathrm{~A}^{2} \cdot \mathrm{s}\right)$ acting in circuit of ГИТМ-10/350 experienced a thin-walled $(h=1 \mathrm{~mm})$ sheet sample TO roof outer stainless steel 12X18H10T

Fig. 2 shows the waveform of the normalized technical requirements [5] of an aperiodic pulse of temporary form of artificial lightning current $T_{1} / T_{2}=15 / 315 \mu$ s acting in high-current discharge circuit ГИТМ-10/350 prototype ТО steel roof and corresponding practical level I lightning $\left(I_{m L} \approx 184 \mathrm{kA} ; T_{1} \approx 15 \mu \mathrm{s}\right.$; $T_{2} \approx 315 \mu \mathrm{s} ; q_{L} \approx 81.3 \mathrm{C} ; J_{L} \approx 7.88 \cdot 10^{6} \mathrm{~A}^{2} \cdot \mathrm{s}$ ).

From local hopping «progress» in Fig. 2 short pulse hitting the artificial lightning current curve (its decline) in the discharge circuit powerful electrical ГИТМ-10/350 $\left(U_{c 1-3} \approx 31 \mathrm{kV} ; U_{c 4} \approx 9.4 \mathrm{kV}\right.$ ) placed on experimental research test range at the Scientific-\&-Research Planning\&-Design Institute «Molniya» of the NTU «KhPI» (at the Department No. 4 «Electromagnetic research and testing») flowing through the sample experienced sheet metal roofing and TO measuring coaxial shunt type ШК300 , it follows that the lightning impulse current $i_{L}(t)$ with said normalized by [ 5] $J_{L} \approx 7.88 \cdot 10^{6} \mathrm{~A}^{2} \cdot \mathrm{s}$ action integral value leads to a large electrothermal and electrodynamic effects not only on the steel sample analyzed (Fig. 3), but also on the conductive structural elements used coaxial shunt. We point out that the resistance of high-current circuit bifilar shunt type ШК-300 was $R_{i} \approx 0.2 \mathrm{~m} \Omega[1,4]$. Numerical evaluation of $W_{i}$ thermal energy released during high-conducted experiments on high-resistance nichrome thin-walled disk used measuring shunt type ШК-300 [4], can be performed by the following approximate formula:

$$
W_{i} \approx R_{i} J_{L}
$$

From (11) at the indicated initial data $\left(R_{i} \approx 0.2 \mathrm{~m} \Omega\right.$; $\left.J_{L} \approx 7.88 \cdot 10^{6} \mathrm{~A}^{2} \cdot \mathrm{s}\right)$ it follows that in this experiment $\left(I_{m L} \approx 184 \mathrm{kA} ; T_{1} \approx 15 \mu \mathrm{s} ; T_{2} \approx 315 \mu \mathrm{s} ; q_{L} \approx 81.3 \mathrm{C}\right)$ at the measuring shunt type ШК-300 (mainly on its highresistance nichrome thin-walled disk) energy is released about $W_{i} \approx 1.6 \mathrm{~kJ}$. 


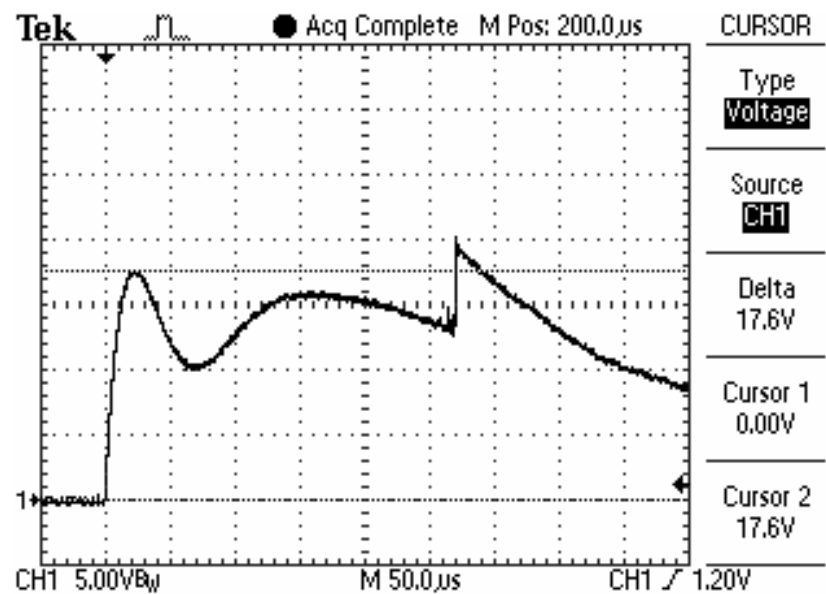

Fig. 2. Waveform of normalized aperiodic current of artificial lightning pulse temporal shape $15 / 315 \mu$ s with amplitude $I_{m L}$ $\approx 184 \mathrm{kA}\left(q_{L} \approx 81.3 \mathrm{C} ; J_{L} \approx 7.88 \cdot 10^{6} \mathrm{~A}^{2} \cdot \mathrm{s}\right)$ acting in a chain ГИТМ-10/350 experienced a thin-walled $(h=1 \mathrm{~mm})$ sheet sample TO roof outer stainless steel 12X18H10T

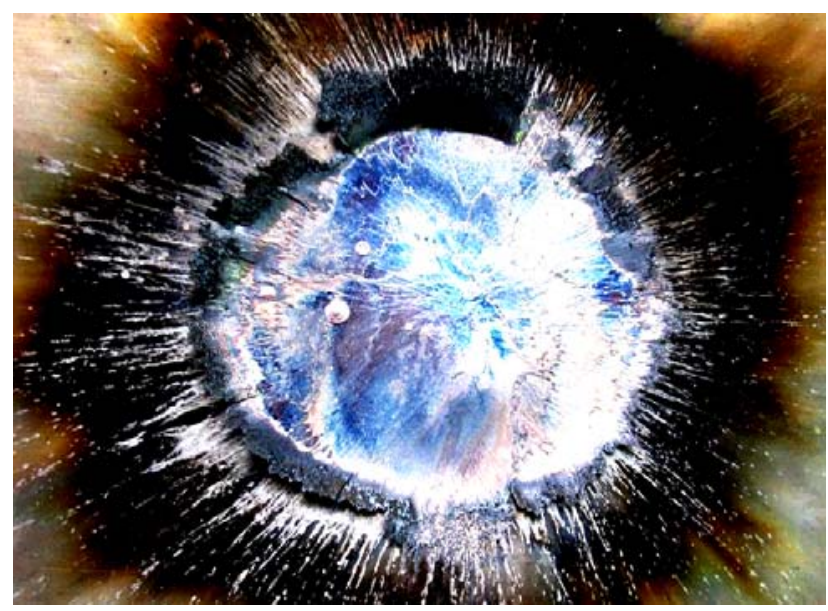

Fig. 3. Results of electrothermal effect of current normalized aperiodic pulse temporal shape of artificial lightning $15 / 315$ microseconds with an amplitude $I_{m L} \approx 184 \mathrm{kA}$ at experienced walled $(h=1 \mathrm{~mm})$ of a sample of the roof that of stainless steel 12X18H10T

Performed at a high-voltage high-current installation ГИТМ-10/350 experiments have shown that the measuring coaxial shunt type ШК-300 [4] the development of the Scientific-\&-Research Planning-\&Design Institute «Molniya» NTU «KhPI» (Department No. 3 «High-voltage impulse technology») is almost the explosive release it by effects electric explosion (EE) of its metal thin-walled nichrome disc [15] of the amount of thermal energy can not withstand $W_{i}$. Conducted extreme experiments have shown that the quantity allocated for measuring coaxial shunt ШК-300 [4] $W_{i}$ thermal energy from flowing through it of an aperiodic pulse of temporary form of artificial lightning current $T_{1} / T_{2}=15 / 315 \mu$ s must not exceed the numerical value equal to $0.5 \mathrm{~kJ}$. This value corresponds to the thermal power $W_{i}$ III-IV levels of lightning protection, when $I_{m L}$ $\approx 100 \mathrm{kA}[5,19]$. In this case, a common indicator of dissipation high resistance nichrome thin-disk meter coaxial shunt ШК-300 thermal energy is the maximum allowable energy density of $W_{i} / R_{i}$ equal to the maximum allowable integral action of the lightning current pulse $J_{L i}$ and number about $2.5 \cdot 10^{6} \mathrm{~J} / \Omega$.

Fig. 4 shows the external view of the measuring coaxial shunt type ШК-300 [4], both before and after flowing through it in high-current discharge circuit ГИТМ-10/350 current normalized aperiodic pulse temporal shape of artificial lightning $15 / 315 \mu \mathrm{s}$ with amplitude $I_{m L} \approx 184 \mathrm{kA}\left(q_{L} \approx 81.3 \mathrm{C} ; J_{L} \approx 7.88 \cdot 10^{6} \mathrm{~A}^{2} \cdot \mathrm{s}\right)$. It is evident that this momentum short simulated lightning strike current results due to a certain part of the EE nichrome thin-walled metal disc measuring coaxial shunt type ШК-300 [4], accompanied by a sharp rise in pressure inside the coaxial design of the shunt, to its destruction and damage.

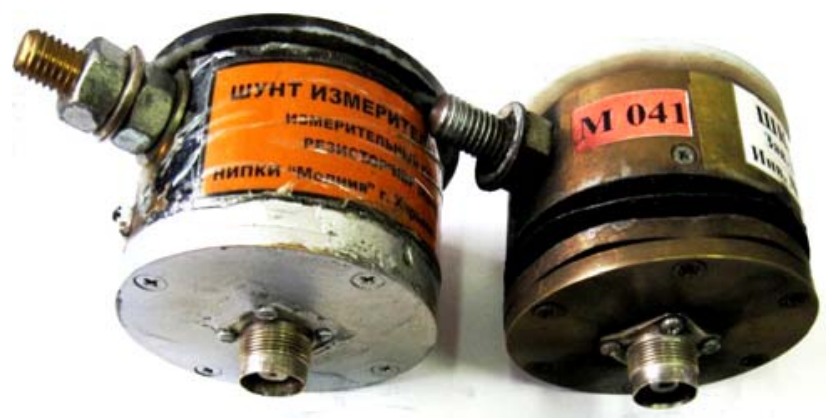

Fig. 4. General view of the measuring coaxial shunt type ШК-300 before (left) and after (right) flow through it in highcurrent discharge circuit of the ГИТМ-10/350 normalized artificial lightning current aperiodic pulse temporal shape $15 / 315 \mu$ s with amplitude $I_{m L} \approx 184 \mathrm{kA}\left(q_{L} \approx 81.3 \mathrm{C}\right.$; $\left.J_{L} \approx 7.88 \cdot 10^{6} \mathrm{~A}^{2} \cdot \mathrm{s}\right)$

From the data in Fig. 3 shows that the direct impact on the prototype sheet sample TO roof stainless steel 12X18H10T thickness $h=1 \mathrm{~mm}$ current normalized aperiodic pulse temporal shape of artificial lightning $15 / 315 \mu$ s with amplitude $I_{m L} \approx 184 \mathrm{kA} \quad\left(q_{L} \approx 81.3 \mathrm{C}\right.$; $J_{L} \approx 7.88 \cdot 10^{6} \mathrm{~A}^{2} \cdot \mathrm{s}$ ) formed in the discharge circuit ГИТМ$10 / 350$, leads to substantial thermal damage only it (samples) in the outer surface of the rounded area on its cylindrical peg of a high air channel simulated lightning spark discharge at the stage of short shot. The radius of thermal damage to the area under consideration corresponds to the radius of the steel coating $r_{0} \approx 0,093 \cdot\left(I_{m L}\right)^{1 / 3} \cdot\left(t_{m L}\right)^{1 / 2}$ according to the Braginsky formula for heavy air plasma channel artificial lightning $[6,7]$, is about $27 \mathrm{~mm}$. One feature of the damaged area is education for its rounded perimeter sticking out in isolation from the outside of the surface of the steel sheeting spiked «beard» of up to $15 \mathrm{~mm}$ with a thickness of about 40 microns. The formation of such a «beard» under the direct influence of the air at the material steel cover short stroke artificial lightning current pulse temporal form $T_{1} / T_{2}=15 / 315 \mu$ s due to surface melting steel coating round anchor zone on its channel of 
lightning, followed by a radial discharge to the outside the molten metal due to acting on it electrodynamic Lorentz force [12]. Examination epicenter zone of thermal damage to the test-discharge circuit ГИТМ-10/350 ТО steel coating shows that in this case $\left(I_{m L} \approx 184 \mathrm{kA} ; q_{L} \approx 81.3 \mathrm{C}\right.$; $\left.J_{L} \approx 7.88 \cdot 10^{6} \mathrm{~A}^{2} \cdot \mathrm{s}\right)$ the depth of the well $h_{m}$ penetration wall stainless steel coating $12 \mathrm{X} 18 \mathrm{H} 10 \mathrm{~T}(h=1 \mathrm{~mm})$ of not more than 42 microns. This empirically derived numerical value of the depth $h_{m}$ practically corresponds to its estimated value determined previously by (8).

\section{Conclusions.}

1. The results of estimates calculated and experimental studies at the Scientific-\&-Research Planning-\&-Design Institute «Molniya» NTU «KPI» electrothermal resistance experienced leaf samples outer roof to protect what in terms of size $500 \times 500 \mathrm{~mm}$ stainless steel $12 \mathrm{X} 18 \mathrm{H} 10 \mathrm{~T}$ thickness $h=1 \mathrm{~mm}$ to the direct impact on them air standardized by the International Standard IEC 62305-12010 artificial lightning aperiodic current pulse of temporal shape $10 / 350 \mu$ s with corresponding tolerances at its ATP indicate that the tested thin-walled steel TO samples are only local surface thermal damage. At said step of pulse current short pin artificial air lightning satisfying the requirements of I-IV levels lightning TO depth $h_{m}$ wells subsurface penetration wall $(h=1 \mathrm{~mm})$ of the test steel coating is less than $50 \mu \mathrm{m}$, and its maximum radius $r_{0}-30 \mathrm{~mm}$.

2. It was found that the maximum permissible level of thermal $W_{i}$ energy dissipated measuring coaxial shunt ШК-300 with high resistance nichrome thin-disk in highcurrent discharge circuit of high-voltage electrical ГИТМ-10/350 normalized by the International Standard IEC 62305-1-2010 current aperiodic pulse of artificial lightning of temporary form $15 / 315 \mu \mathrm{s}$, its numerical value is not greater than $0.5 \mathrm{~kJ}$ and meets the requirements of III-IV levels of lightning TO. This limit value specified shunt dissipation of thermal energy corresponds $W_{i}$ for it such a generalized indicator of how specific they dissipated heat energy is defined as $W_{i} / R_{i}$ and numerically equal to the maximum allowable for its circuit with resistance $R_{i}$ integral action artificial lightning current pulse $J_{L i} \approx 2.5 \cdot 10^{6} \mathrm{~J} / \Omega$.

\section{REFERENCES}

1. Baranov M.I., Kniaziev V.V., Kravchenko V.I., Rudakov S.V. Results of calculation-experimental investigations of electro-thermal resistibility of sheet steel samples to action of rationed components of pulsed current of artificial lightning. Electrical engineering \& electromechanics, 2016, no.3, pp. 40-49. (Rus). doi: 10.20998/2074-272X.2016.3.07. 2. SAE ARP 5412: 2013. Aircraft Lightning Environment and Ralated Test Waveforms. SAE Aerospace. USA, 2013.pp. 1-56.

3. SAE ARP 5416: 2013. Aircraft Lightning Test Methods. SAE Aerospace. USA, 2013. - pp. 1-145.

4. Baranov M.I., Koliushko G.M., Kravchenko V.I., Nedzel'skii O.S., Dnyshchenko V.N. A Current Generator of the Artificial Lightning for Full-Scale Tests of Engineering
Objects. Instruments and Experimental Technique, 2008, no.3, pp. 401-405. doi: 10.1134/s0020441208030123.

5. IEC 62305-1: 2010 «Protection against lightning. Part 1: General principles». Geneva, IEC Publ., 2010.

6. Lozanskiy E.D., Firsov O.B. Teorija iskry [Theory of spark]. Moscow, Atomizdat Publ., 1975. 272 p. (Rus).

7. Baranov M.I. Izbrannye voprosy elektrofiziki. Tom 2, Kn.

2: Teoriia elektrofizicheskikh effektov $i$ zadach [Selected topics of Electrophysics. Vol.2, Book 2. A theory of electrophysical effects and tasks]. Kharkiv, NTU «KhPI» Publ., 2010. 407 p. (Rus).

8. Rayzer Yu.P. Fizika gazovogo razrjada [Physics of gas charge]. Moscow, Nauka Publ., 1987. 592 p. (Rus).

9. Kuzhekin I.P., Larionov V.P., Prohorov E.N. Molnija $i$ molniezashchita [Lightning and protection from lightning]. Moscow, Znak Publ., 2003. 330 p. (Rus).

10. Abramov N.R., Kuzhekin I.P., Larionov V.P. Characteristics of penetration of the walls of metal objects when exposed to lightning. Electricity, 1986, no.11, pp. 22-27. (Rus).

11. Baranov M.I. An approximate calculation of the maximum temperature of the plasma in high-current highvoltage spark discharge channel switch air atmospheric pressure. Tekhnichna Elektrodynamika, 2010, no.5, pp. 18-21. (Rus).

12. Kuz'michev V.E. Zakony i formuly fiziki [Laws and formulas of physics]. Kiev, Naukova Dumka Publ., 1989. 864 p. (Rus).

13. Available

at:

http://www.sgkarkas.ru/spravochnik/marochnik_stalej/12h18 n10t (Accessed 11 July 2015).

14. Baranov M.I. Izbrannye voprosy elektrofiziki. Tom 3: Teorija i praktika elektrofizicheskih zadach [Selected topics of Electrophysics. Vol. 3: Theory and practice of electrophysics tasks]. Kharkiv, Tochka Publ., 2014. 400 p. (Rus).

15. Baranov M.I. Izbrannye voprosy elektrofiziki: Monografija $v$ 2-h tomah. Tom 2, Kn. 1: Teorija elektrofizicheskih effektov $i$ zadach [Selected topics of Electrophysics: Monograph in 2 vols. Vol. 2, book. 1: Theory of electrophysics effects and tasks]. Kharkov, NTU «KhPI» Publ., 2009. 384 p. (Rus).

16. Dashuk P.N., Zayents S.L., Komel'kov V.S., Kuchinskiy G.S., Nikolaevskaya N.N., Shkuropat P.I., Shneerson G.A. Tehnika bol'shih impul'snyh tokov $i$ magnitnyh polej [Technique large pulsed currents and magnetic fields]. Moscow, Atomizdat Publ., 1970. 472 p. (Rus).

17. Gulyi G.A. Nauchnye osnovy razriadno-impul'snykh tekhnologii [Scientific basis of the discharge-pulse technology]. Kiev, Naukova Dumka Publ., 1990. 208 p. (Rus). 18. Mesiats G.A. Impul'snaja energetika $i$ elektronika [Pulsed power and electronics]. Moscow, Nauka Publ., 2004. 704 p. (Rus).

19. Baranov M.I., Koliushko G.M., Kravchenko V.I., Rudakov S.V. A powerful high-voltage generator of aperiodic impulses of current of artificial lightning with the peak-temporal parameters rated on an International Standard IEC 62305-1-2010. Electrical engineering \& electromechanics, 2015, no.1, pp. 51-56. (Rus). doi: 10.20998/2074-272X.2015.1.10.

20. Baranov M.I., Koliushko G.M., Kravchenko V.I., Rudakov S.V. A generator of aperiodic current pulses of 
artificial lightning with a rationed temporal form of 10 $\mu \mathrm{s} / 350 \mu \mathrm{s}$ with an amplitude of $\pm(100-200) \mathrm{kA}$. Instruments and Experimental Techniques, 2015, vol.58, no.6, pp. $745-750$. doi: 10.1134/s0020441215060032.

Received 29.08.2016
${ }^{1}$ Scientific-\&-Research Planning-\&-Design Institute «Molniya», National Technical University «Kharkiv Polytechnic Institute», 47, Shevchenko Str., Kharkiv, 61013, Ukraine, phone +38 057 7076841, e-mail: eft@kpi.kharkov.ua ${ }^{2}$ National University of Civil Protection of Ukraine, 94, Chernyshevska Str., Kharkiv, 61023, Ukraine, phone+38057 7073438, e-mail: serg_73@i.ua

M.I. Baranov ${ }^{1}$, Doctor of Technical Science, Chief Researcher,

V.V. Kniaziev ${ }^{1}$, Candidate of Technical Science, Senior

Research Scientist,

S.V. Rudakov ${ }^{2}$, Candidate of Technical Science, Associate

Professor,

\section{How to cite this article:}

Baranov M.I., Kniaziev V.V., Rudakov S.V. Calculation and experimental estimation of results of electro-thermal action of rationed by the international standard IEC 62305-1-2010 impulse current of short blow of artificial lightning on the thin-walled coverage from stainless steel. Electrical engineering \& electromechanics, 2017, no.1, pp. 31-38. doi: 10.20998/2074-272X.2017.1.06. 